\title{
Analysis of spatial and environmental justice in three Mexican cities
}

\author{
L Araujo-Alvarado $^{1,}$, C Y Ortega-Montoya ${ }^{2 *}$, and A Ávila-Galarza ${ }^{1}$ \\ ${ }^{1}$ Facultad de Ingenieria, Universidad Autonoma de San Luis Potosí, Av. Manuel Nava \#8, Zona \\ Universitaria, 78290, San Luis Potosi, Mexico \\ ${ }^{2}$ Escuela de Humanidades y Educacion. Tecnologico de Monterrey, Av. Pedro Coronel No.16, \\ Dependencias Federales, 98600, Guadalupe, Zacatecas, Mexico
}

\begin{abstract}
The accelerated growth of cities in developing countries poses a challenge for urban planning such as guaranteeing the safety of all inhabitants from natural and anthropogenic threats. The objective of this study is to determine the urban areas and social sectors of three medium sized Mexican cities that are exposed to high risk activities. The results indicate that for the metropolitan area of San Luis Potosi, 57.6\% of high risk activities are within the urban sprawl, while $100 \%$ are in the cities of Zacatecas and Fresnillo. In all three case studies, most of the activities studied are in areas with low and medium rates of marginalization. In San Luis Potosi, $4.1 \%$ are in areas with high and very high population density but none of the case studies showed a conglomeration of these types of risks in a determined area of the cities. A database of companies with high risk activities, regulated at a federal level, public became public in Mexico in 2014. This information is of great value at a local level to define the strategies of land use planning that guarantee access to environmental justice as well as effective prevention strategies and responses to chemical emergencies.
\end{abstract}

\section{Introduction}

The United Nations Development Programme (UNDP) has presented within its sustainable development objectives the construction of sustainable cities and communities, therefore recognizing that currently half of the population lives in urban areas and that by the year 2050 it will increase to two thirds. Because of this, it is of great importance to transform and efficiently manage urban spaces.

A problem related to the accelerated growth of urban areas is the formation of poverty belts around cities where the poorest inhabitants tend to settle erratically. The urban space is therefore spatially configured in relation to the social sectors that inhabit the different areas of the city. One of the challenges to urban management is the prevention, preparation and response to environmental risks of not only natural but also anthropogenic origin.

\footnotetext{
*Corresponding author: yazmin.ortega@tec.mx
} 
Cannon [1] states that social processes create an uneven exposure to risk, thus making some sectors of the population more susceptible to suffering disasters than others.

Chemical risks are relevant because industrial spaces for the transformation of consumer goods are grouped within the city. The analysis of risk scenarios is important because it allows us to identify the most susceptible groups of a population or ecosystem that can be exposed during a possible disaster. An adequate management of risk is the only guarantee in facing the future with a solid and secure foundation [2]. For this reason, since 1992, the United Nations has recognized the importance of chemical risks in urban environments through the APELL program, which establishes that a better understanding of risk scenarios and the mechanisms for prevention and protection in case of emergency are vital for the construction of capabilities within a society and the agencies in charge of public safety.

According to these scenarios, it is very important that the instruments for land use planning, such as the case of the ecological and environmental management, incorporate into their diagnostic, prognostic and resulting programs, the consideration of risk analysis for the different existing hazards, thus identifying the level of vulnerability of the population for each one of them [3]. Recognizing the conditions of vulnerability as risk generators, and therefore as generators of disaster, has a political dimension. It implies recognizing that in situations of risk and disaster there is social and political responsibility thus referring to notions of environmental justice [4].

While people have the right to a safe and clean environment, research in environmental justice has shown that lower and middle class communities have a greater exposure to higher levels of risk than other groups in society [5]. The environmental justice concept was developed in the United States due to a movement that sought equality in the distribution of environmental risks among ethnic and racial groups. This is to say; all people have the right to be protected from pollution and to live and enjoy a safe and clean environment [6].

Environmental justice establishes that groups with a high concentration of low-income families or racial and ethnic minorities are more exposed to a series of higher environmental risks and problems. These groups also do not equally benefit from the positive implications derived from environmental policies and regulation [7]. According to environmental justice studies, the most common sources of risk tend to be facilities with toxic emissions, landfills and industrial zones. Several studies have shown that a significant relation exists between the proximity of environmental risks and health problems such as respiratory conditions, pregnancy problems (malformations, injury to the central nervous system of the fetus), child cancer, leukemia and kidney disease, among others. Although the population that is close to these sources of risk seems to be more likely to have these diseases or health problems, the proximity is not equivalent to the individual exposure and the negative impact is not the same for all inhabitants [8].

In addition to this, in their research, Cole, Elliott and Khemmarat [9] found that ethnic division and polarization of communities have a positive and statistically significant correlation with toxic releases. This suggests that, under equal conditions, the greater the ethnic divisions within an area, the greater the level of toxic emissions will be. Another important aspect in case studies of environmental justice is the use of Geographic Information Systems (GIS) as a way of exploring spatial relations between factors that can be associated with the locations of risk facilities. Population density, land use and employment are factors that can be used to predict the installation of emission sources [10].

Ash et al. [11] indicates that while it is true that a larger number of cases where there is a lack of environmental justice have been present in minorities such as ethnic groups, lowincome populations and immigrants (some authors even include pregnant women, children and senior citizens in this term), this is a problem that encompasses all society. They 
suggest that urban areas that contain minorities experiment exposure to pollution but in the end, this is a problem that affects all subgroups of a population. Their conclusion is that access to environmental justice is good for everyone, not just for minority groups.

\subsection{Regulation of risk activities in Mexico}

In Mexico, high risk activities are defined as service, commercial or industrial sites where materials with explosive, toxic or flammable characteristics, that exceed the quantities published in the First and Second High Risk Activities List, are generated or handled. These activities are regulated at a federal level.

The storage of these hazardous substances represents a chemical threat that can affect the environment or the population's health if an accidental release of one of these substances were to occur. The analysis of high risk activities in Mexico was possible due to the approval of the General Act of Transparency and Access to Public Information and consequently has opened up information at a federal level. Thanks to this law and through a request for public information it was possible to learn about the high risk activities that are present in the national territory and that previously were considered classified information that could not be accessed.

\section{Case studies}

The metropolitan area of San Luis Potosi-Soledad de Graciano Sanchez is considered the $11^{\text {th }}$ largest in the country $(1,040,443$ people) and one of the most important in the state since a third of the services and population are centered there. The urban area of San Luis Potosi has gained economic, political and social importance due to its proximity to the three main population centers in the country (Mexico City, Guadalajara and Monterrey). Likewise, the city is part of two important trade corridors in the country: the road and rail network that connect the central-northern part of the country (the core of NAFTA) and the network that connects the Gulf of Mexico and Pacific Ocean seaports. This confirms its favored position as a cultural, industrial, commercial and logistical zone.

The metropolitan area of Zacatecas (275,027 people) is experiencing an important population growth and currently ranks 43 out of 56 in the national urban system with a little more than 270 thousand inhabitants. On the other hand, the city of Fresnillo has been the most populated municipality in the state of Zacatecas for 50 years $(230,865$ people). The main problems of this city are centered on a deficient urban structure that is due to the disorderly growth of the city and to an indiscriminate mixture of land use that presents a marked incompatibility.

The case studies and their population are shown in figure 1.

Fig. 1. Location of case studies.

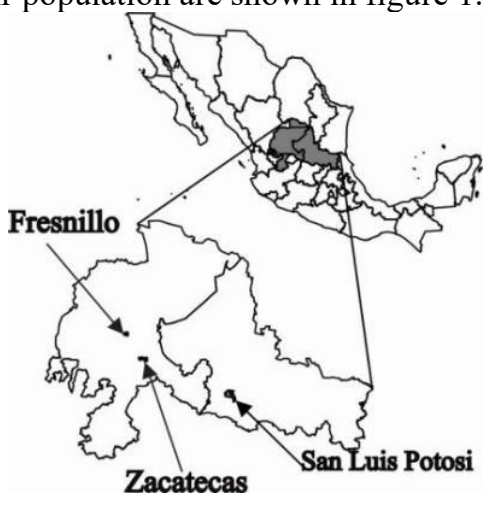




\section{Methodology}

This research was developed following the subsequent stages:

\subsection{Consultation of the National Register of high risk activities}

The National Register of companies with high risk activities was obtained through a public information request that was submitted to the Secretariat of Environment and Natural Resources (SEMARNAT) in 2014.

\subsection{Update of the National Register of high risk activities}

The addresses and main information of companies with high risk activities (such as business name, address and state) were verified through a consultation of the National Institute of Statistics and Geography's [12] National Directory of Economic Units (DENUE). Said directory offers the identification details, location, economic activity and size of the companies active in the national territory.

\subsection{Geographic positioning of risk activities}

The high risk activities were geographically arranged using the information from DENUE and the geographic information system ArcMap 10.1.

\subsection{Delimitation of industrial areas}

Industrial zones were delimitated within the cities studied using Google Earth. In the case of San Luis Potosi, the secondary zoning plan of the 2003 Strategic Population Central Plan of San Luis Potosi-Soledad de Graciano was used. For Zacatecas, the current urban land use plan of the 2016 Urban Development Plan of Zacatecas-Guadalupe was used. In the case of the city of Fresnillo, the zones were defined using the Google Earth tool, considering the connectivity and aggregation level of the industrial infrastructure.

\subsection{Consultation of social development benchmarks}

The 2010 Urban Marginalization Index was consulted for the areas studied at the level of a Basic Geostatistical Area (AGEB). This index is developed by the National Population Council [13] and is included in the INEGI's Census Information Consult System (SCINCE).

\subsection{Consultation of population density}

The population density of the AGEB's studied was obtained from the total population variables available in the 2010 Housing and Population Census [14]. The ArcMap tool "calculate geometry" was used to obtain the area of the AGEB's in $\mathrm{km}^{2}$ units.

$$
\text { Population Density }=\frac{\text { Population }(\text { Inhab) }}{\text { Surface }\left(\mathrm{km}^{2}\right)}
$$

\subsection{Environmental justice analysis}

The level of social marginalization and population density of the basic geostatistical areas (AGEB) where the companies with high environmental risk are located were analyzed. An AGEB is a polygon that groups between 25 and 50 city blocks. 
The population density and social marginalization information are important variables for the analysis of risk scenarios since they allow us to identify the characteristics of the systems potentially affected and the conditions of social vulnerability.

\section{Results}

According to the National Register of High Risk Activities, in San Luis Potosi there are 73 high risk activities. $57.6 \%$ of companies considered as high risk are located within the industrial zone of the city, while $42.4 \%$ are dispersed throughout the urban and suburban areas (Figure 2a). In the case study of the Zacatecas metropolitan area, there are 6 companies with high risk activities. None of these companies are located within the industrial polygon, but rather are located in areas destined for commercial and residential use in the center and outskirts of the metropolitan area (Figure 2b). The same occurs for Fresnillo where the 11 companies with high risk activities are located within the urban sprawl (Figure 2c.)
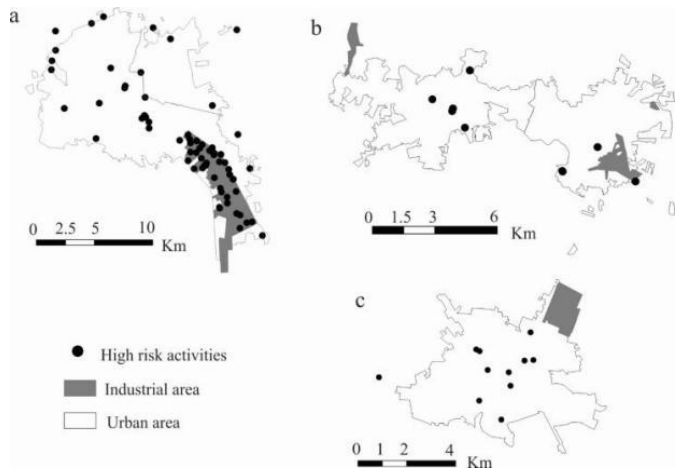

Fig. 2. Companies with high environmental risk in the metropolitan areas of a) San Luis Potosi, b)Zacatecas and c) Fresnillo Source:[12].

In the three case studies the high risk activities are randomly distributed among the different sectors of the cities without a particular pattern for these type of activities.

It was found that the most frequent high risk activities in the capital of San Luis Potosi are: the production of chemical products and the storage and sale of LP gas. While in Zacatecas it is the sale of LP gas and the production of ice. Finally, a mining company with high risk activities is located within the metropolitan area of Zacatecas (Table 1).

Table 1. Main activities of the companies with high risk activities ${ }^{\mathrm{a}}$

\begin{tabular}{|c|c|c|}
\hline \multirow{2}{*}{ Main Activities } & \multicolumn{2}{|c|}{ Number of companies } \\
\cline { 2 - 3 } & San Luis Potosi & Zacatecas \\
\hline Treatment plants and hazardous waste treatment & 7 & - \\
\hline LP and butane gas storage and distribution & 9 & 5 \\
\hline Pemex & 3 & 1 \\
\hline Manufacturing of chemical products & 12 & - \\
\hline Ice Manufacturing & 4 & 4 \\
\hline Automotive companies & 7 & 3 \\
\hline Food industry & 10 & 2 \\
\hline Mining & - & 1 \\
\hline Others & 21 & 2 \\
\hline
\end{tabular}

${ }^{\text {a }}$ Source: National Directory of Economic Units (DENUE).

\subsection{Social vulnerability}


The location of the companies with high risk activities was correlated to the rate of marginalization of the basic geostatistical areas. In the case of the metropolitan area of San Luis Potosi the results obtained were: $28.8 \%$ of the companies are located in areas with low and very low rate of marginalization, the majority of these are located near the industrial zone and the center of the urban sprawl, $9.6 \%$ in areas of medium marginalization and only $1.3 \%$ in areas with a high rate of marginalization, primarily in the outskirts of the city (Figure 3a). On another note, $60.3 \%$ of said companies are found in areas where the degree of marginalization is unknown.

In the metropolitan area of Zacatecas (Figure 3b), 50\% of the high risk activities studied are located in areas classified with a low rate of marginalization, $33.3 \%$ in areas with a very low rate and $16.7 \%$ in areas without data. In the case of the city of Fresnillo (Figure 3c), $63.6 \%$ of the companies with high risk activities are located in areas with a low rate of marginalization, while only $27.3 \%$ are situated in areas with a medium rate and $9.1 \%$ in areas without data.

It is important to note that the areas where information on the level of marginalization does not exist tend to be areas without human settlements or non-urban towns with a population of less than 2,500 inhabitants.

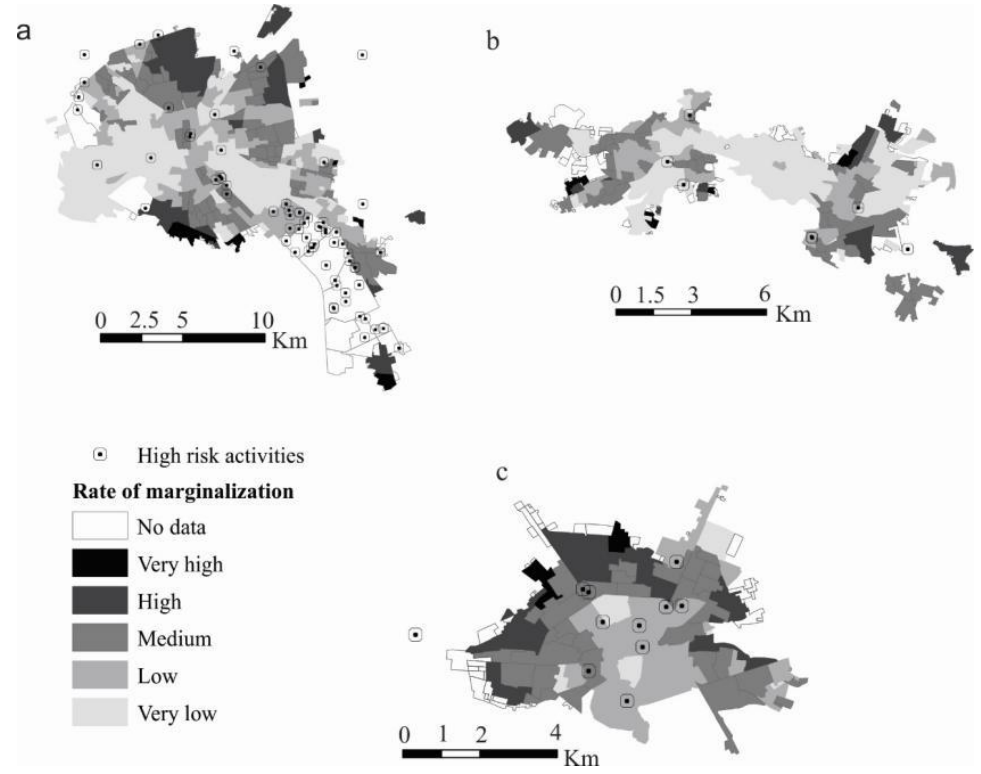

Fig. 3. Marginalization rate in the case studies a) San Luis Potosi, b) Zacatecas and c) Fresnillo. Source [12][13].

\subsection{Population density}

The analysis of the population density by AGEB in the urban area of San Luis Potosi shows that $48 \%$ of companies with high risk activities are located in AGEBs with very low population density. As we can observe in figure $4 \mathrm{a}, 16.4 \%$ of said companies are in areas with low and very low density, $13.7 \%$ present no data, $11 \%$ with medium density, $6.8 \%$ with hih density and $4.1 \%$ of them are in AGEBS with very high density, especially in the eastern part of the city.

In the case of the urban area of Zacatecas, $50 \% \%$ of high risk activities are located to the north of the city in areas with high population density. $16.6 \%$ show no data. The three remaining companies $(50 \%)$ are in medium population density areas as shown in figure $4 \mathrm{~b}$. 
In the city of Fresnillo, 54.5\% of high risk companies are in areas with medium and low population density. $36.4 \%$ are located in areas with high density and $9.1 \%$ show no data (Figure 4c).
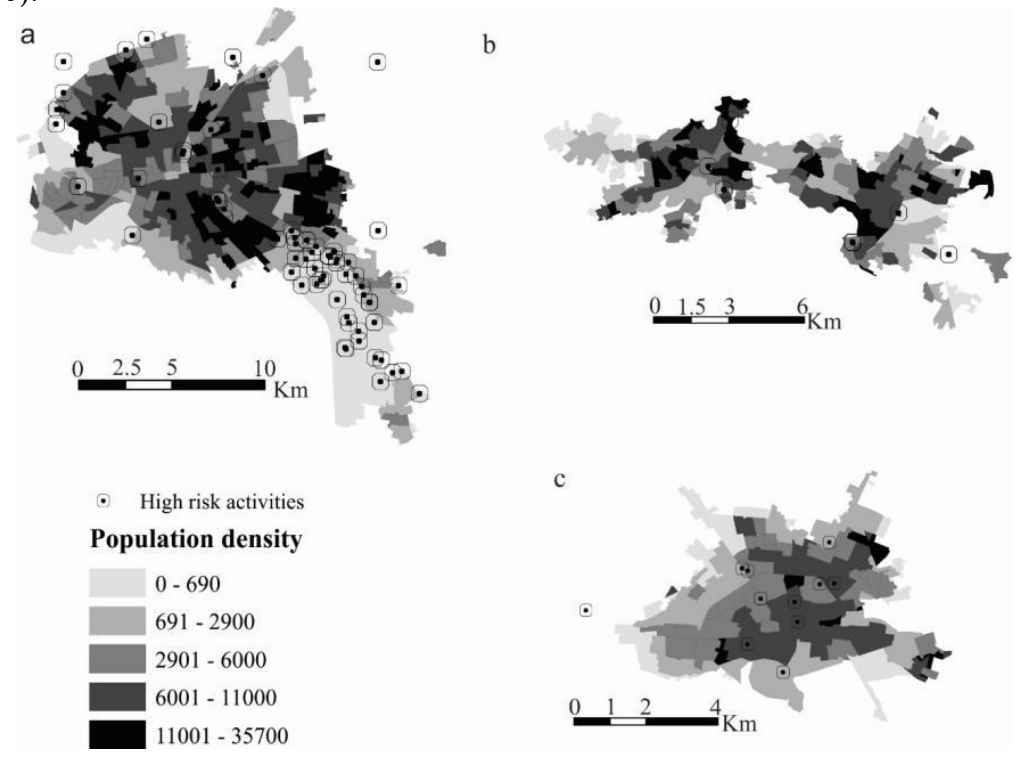

Fig. 4. Population density in the case studies a) San Luis Potosi, b)Zacatecas and c) Fresnillo. Source $[12][14]$

\section{Discussion}

In the case of San Luis Potosi it was found that $57 \%$ of the companies are located in areas with industrial land use vocation, while the rest of the companies are located in the interior of the urban sprawl. This is in contrast to the Population Central Plan of San Luis PotosiSoledad de Graciano which establishes that all types of industry or large-scale storage that have high risk and/or pollution characteristics must be located in industrial areas or corridors designed for that purpose.

The analysis of the degree of marginalization per urban AGEB indicates that in San Luis Potosi only one high risk company exists in an AGEB with a very high degree of marginalization (in the outskirts of the city). However, a large number of companies are located in the surroundings of the urban sprawl, in areas without data on social marginalization. In areas considered non-urban (with less than 2,500 inhabitants) this variable can have greater relevance in the study of risk scenarios. Ortega [15] indicates that rural settlements are not included in urban marginalization rates, but that one would expect greater vulnerability from this scenario due to its poverty conditions which represents a lower response in an emergency.

In the three case studies of companies with high risk activities, the number of inhabitants near these activities turned out to be the variable with the most critical aspect. This is due to the fact that the companies are located in urban areas where the population density is high and job opportunities reduce the rate of marginalization.

With respect to the relationship between the degree of marginalization and a greater exposure to risks caused by companies with environmental hazards, this study found no correlation. This was mentioned by Mennis and Jordan [10] who claimed that while high risk facilities are associated with minority groups in society, there is not a clear pattern in all areas of study. It is important to note however that in other parts of the country this 
situation is in fact related to environmental justice, where low income populations are the ones that are most exposed to sources of danger due to high risk activities.

\section{Conclusion}

The analysis of the social marginalization and population density variables in the urban areas of San Luis Potosi, Zacatecas and Fresnillo were useful in identifying the distribution of chemical and technological risks. Thus confirming the presence of high risk activities not in industrial zones, but rather in areas with commercial and residential use within the urban sprawl.

The program that governs the city's growth in the metropolitan area of San Luis Potosi has not been updated in more than 14 years. Another important point is that none of the cities studied has spatial planning.

In the three cases studied, most of the companies were in areas with low and medium rates of marginalization. There is only one case in the northern part of San Luis Potosi where a company exists in an AGEB with a very high level of marginalization. In San Luis Potosi there is a greater proximity between high risk activities and areas with high population density. Particularly interesting is where people are living close to a source of danger with the risk of an accident happening that can affect the health of the population and the environment. The dissemination of information regarding the risk of living near a high risk activity and training the population on what measures to take in case of a leak, fire or explosion, are effective strategies that can be used to decrease their vulnerability and increase their responsiveness in an emergency.

State and municipal governments in the areas studied must develop (or update) their urban planning instruments based on adequate ecological and spatial planning. The proposal and execution of pertinent corrective measures that contribute to the decrease of high risk activities in commercial and residential areas is also necessary.

The dissemination and access to the information gathered in this type of research project is important as it leads to the development of better urban planning policies, results in actions that decrease the vulnerability of people and establishes proof and precedents useful in improving access to environmental justice.

\section{Acknowledgments}

To the Engineering Department at the Autonomous University of San Luis Potosi and the Urban Development Secretariat of San Luis Potosi and Zacatecas.

\section{References}

1. Cannon T 2000 Vulnerability Analisys and Disaster Flood Ed Parker D J 45-55 (Oxford: Routledge)

2. Maturana P A 2011 Evaluación de riesgos y gestión en desastres. 10 preguntas para la década actual Rev Méd Clín Las Condes. 22 545-55

3. Rivera E, Palacio G, Villalobos G, Silva R and Afonso P 2004 Evaluación de daños en las zonas costeras de la península de Yucatán por el huracán "Isidoro". Desarrollo de Propuestas de Investigación y Mitigación en Manejo Integrado de Recursos Costeros. Sección Campeche, (Campeche: Universidad Autónoma de Campeche) 
4. Campos M, Toscana A and Alanís J 2015 Riesgos socionaturales: vulnerabilidad socioeconómica, justicia ambiental y justicia espacial. Cuad Geogr-Rev Col Geogr 24 53-69

5. EPA 1992 Environmental Equity. Reducing risk for all communities. (Washington: Environmental Protection Agency)

6. Hervé D 2010 Noción y elementos de la justicia ambiental: directrices para su aplicación en la planificación territorial y en la evaluación ambiental estratégica. Rev der 23 9- 36. https://dx.doi.org/10.4067/S0718-09502010000100001

7. Arriaga A and Pardo M 2011 Justicia ambiental: estado de la cuestion. Rev Int Sociol Revista v Internacional de Sociología 69 627-48. DOI: 10.3989/2009.12.210

8. Maantay J, Chakraborty J and Brender J 2011 Proximity to Enviromental Hazards: Environmental Justice and Adverse Health Outcomes. Strengthening Enviromental Justice Research and Decision Making: A Symposium on the Science of Disproportionate Enviromental Health Impacts (Washington: Environmental Protection Agency)

9. Cole M A, Elliott R J and Khemmarat K 2013 Local exposure to toxic releases: Examining the role of ethnic fractionalization and polarisation Ecol econ, 93 249-259.

10. Mennis J and Jordan L 2005 The Distribution of Enviromental Equity: Exploring Spatial Nonstrationarity in Multivariate Models of Air Toxic Releases Ann Am Assoc Geogr 95 249- 68

11. Ash M, Boyce J K, Chang G, Pastor M, Scoggins J. and Tran J 2009 Justice in the Air: Tracking Toxic Pollution from America's Industries and Companies to Our States, Cities, and Neighborhoods (Massachusetts; Political Economy Research Institute)

12. INEGI 2014 Directorio Estadístico Nacional de Unidades Económicas. (Aguascalientes: Instituto Nacional de Estadística y Geografía)

13. CONAPO 2010 Indice de Marginación Urbana 2010. Base AGEB Urbanas y Población. (Mexico City: Consejo Nacional Población)

14. INEGI 2010 Censo de Población y Vivienda del año 2010. (Aguascalientes: Instituto Nacional de Estadística y Geografía)

15. Ortega-Montoya C Y 2015 Propuesta Metodológica para la Evaluación del Riesgo Ambiental Debido al Manejo de Materiales Peligroso en el Estado de San Luis Potosí (Mexico City: Repositorio Nacional CONACYT) 